\title{
HUBUNGAN ANTARA PERSEPSI SISWA MENGENAI KOMPETENSI PEDAGOGIK DAN PROFESIONAL GURU DENGAN HASIL BELAJAR SISWA MATA PELAJARAN RANGKAIAN LISTRIK (STUDI KASUS PADA SMKN 26 JAKARTA PAKET KEAHLIAN TEKNIK INSTALASI PEMANFAATAN TENAGA LISTRIK KELAS X)
}

\author{
${ }^{1}$ Azza Muzayanah, ${ }^{2}$ Soeprijanto, ${ }^{3}$ Faried Wadjdi. \\ ${ }^{1,2,3}$ Pendidikan Teknik Elektro,Fakultas Teknik, Universitas Negeri Jakarta \\ ${ }^{1}$ E-mail : azza.muzayanah@gmail.com
}

\begin{abstract}
The studies aims is show The relationship between students's perception of pedagogy and profesional competence teachers with wtudetnts learning achivements (Case Studies on SMKN 26 Jakarta Package Expertse TIPTL grade $X)$.

Studies is done in SMKN 26 Jakarta, held on June 2016. The quantitative metodology with survei by approach associative. The samples were 51 students that is the students on grade X. Is a technique random sampling used in the sample collection. Instrumen used to getting data of X variabel (students's perception about competence teachers) in this reasherch is measured using likert scale while Y Variabel (learning achivements) taken from the value of student's UAS. Data analysis technique start from find regression. The requirements of analysis of normaity test by test lilliforce and it shows that data is normal distribution. Then the hypotesis use the correlation product momment and obtain $r 0,43$ so that it can be said that $X_{1}$ and $X_{2}$ variable have positf relation with $Y$ variable.

The result showed that value $t_{\text {hitung }}$ greater than the $t_{\text {tabel }}(4,57>2,009)$ with significant 0,05 standard, it show that $H_{0}$ was refused so that can be concluced that there is a positive relationship between students 's perception of pedagogy and profesional competence teachers with studetnts learning achivements

Keyword: Students Perseption, Teacher Competence, Learning Achivements.
\end{abstract}

\begin{abstract}
Abstrak
Abstrak Penelitian ini bertujuan untuk mengetahui hubungan antara persepsi siswa mengenai kompetensi Pedagogik dan profesional guru dengan prestasi belajar siswa (studi kasus pada SMKN 26 Jakarta paket keahlian TIPTL kelas X).

Penelitian dilakukan di SMKN 26 Jakarta, dilaksanakan pada bulan Juni 2016. Metode penelitian yang digunakan adalah kuantitatif dengan menggunakan survei dengan pendekatan asosiatif. Sampel yang diteliti berjumlah 51 siswa yaitu siswa kelas X. Adalah teknik random sampling yang digunakan dalam pengambilan sampel. Insturmen yang digunakan untuk memperoleh data variabel X (Persepsi siswa mengenai kompetensi guru) dalam penelitian ini diukur dengan menggunakan skala likert sedangkan variabel Y (Prestasi Belajar) diambil dari nilai UAS siswa. Teknik analisis data dimulai dari mencari persamaan regresi. Uji persyaratan analisis yaitu uji normalitas dengan uji liliefors dan di dapatkan menandakan bahwa data berdistribusi normal. Selanjutnya uji hipotesis menggunakan uji korelasi product moment dan diperoleh $\mathrm{r}$ sebesar 0,43 sehingga dapat dikatakan bahwa variabel $\mathrm{X}_{1}$ dan $\mathrm{X}_{2}$ mempunyai hubungan yang poritif dengan variabel $\mathrm{Y}$.

Hasil penelitian menunjukkan bahwa nilai $t_{\text {hitung }}$ lebih besar dari nilai $t_{\text {tabel }}(4,57>2,009)$ dengan taraf signifikan 0,05 yang artinya $\mathrm{H}_{0}$ ditolak sehingga dapat disimpulkan bahwa terdapat hubungan yang positif dan signifikan antara persepsi siswa mengenai kompetensi pedagogik dan profesional guru dengan prestasi belajar siswa.
\end{abstract}

Kata Kunci: Persepsi Siswa, Kompetensi Guru, Prestasi Belajar.

\section{PENDAHULUAN}

Pembelajaran merupakan salah satu hal yang menjadi kebutuhan bagi setiap individu. Pembelajaran akan memberikan perubahan pada individu. Individu menyadari bahwa proses pembelajaran akan terus di alaminya sepanjang hidup. Belajar juga merupakan salah satu faktor yang yang mempengaruhi dan berperan penting dalam pembentukan pribadi dan prilaku individu.
Menurut Siregar dan Nara (2011 : 3), belajar merupakan sebuah proses yang komplek yang terjadi pada semua orang dan berlangsung seumur hidup, sejak masih bayi (bahkan dalam kandungan) hingga liang lahat.

Keberhasilan proses belajar mengajar dapat di ukur dengan menilai subjek belajar yaitu peserta didik. Untuk melihat keberhasilan proses belajar mengajar pada diri individu adalah dengan melihat hasil belajar individu tersebut. Menurut 
Djamarah dan Zain (2010 : 114) mengatakan bahwa sederetan angka yang terdapat dibuku rapor adalah bukti nyata dari keberhasilan belajar mengajar. Buku rapor tersebut yang merupakan bukti konkrit dari hasil belajar siswa.

Berkaitan dengan prestasi belajar, tentu saja setiap pembelajaran menginginkan hasil belajar yang baik. Hasil belajar yang baik diperlukan strategi - strategi pembelajaran yang mendukung ketercapaian hasil belajar yang baik. Strategi strategi tesebut harus dilakukan oleh pengajar maupun oleh siswa sebagai subjek belajar.

Dalam mencapai hasil belajar yang baik, ada beberapa faktor yang mempengaruhi siswa yaitu faktor eksternal dan faktor internal. Salah satu faktor eksternal yang mempengaruhi prestasi belajar siswa adalah guru. Guru sangat berperan penting dalam proses belajar mengajar dan dalam proses mencapai hasil belajar. Semua guru harus mempunyai kompetensi belajar sesuai dengan Undang - Undang No. 14 Tahun 2005 tentang kompetensi guru dan dosen.

Siswa yang merupakan subjek belajar mempunyai pengaruh besar dalam menentukan hasil belajar. Hasil belajar yang di raih oleh siswa menjadi tolak ukur ketercapaian siswa dalam melakukan proses belajar. Siswalah yang mengikuti kegiatan belajar, yang mempunyai tujuan belajar dan yang memiliki cita - cita dalam belajar. Sehingga siswa adalah salah satu faktor yang perlu diperhatikan dalam mencapai hasil belajar.

Dalam mencapai hasil belajar yang baik, ada beberapa faktor yang mempengaruhi siswa yaitu faktor eksternal dan faktor internal. Salah satu faktor eksternal yang mempengaruhi prestasi belajar siswa adalah guru. Guru sangat berperan penting dalam proses belajar mengajar dan dalam proses mencapai hasil belajar. Semua guru harus mempunyai kompetensi belajar sesuai dengan Undang - Undang No. 14 Tahun 2005 tentang kompetensi guru dan dosen.

Walaupun kompetensi guru sudah diatur oleh Undang - Undang, disekolah guru akan memberikan pengajaran yang berbeda - beda. Hal ini akan menimbulkan persepsi siswa yang berbeda - beda juga terhadap guru. Dari sisi yang lain, siswa juga mempunyai prestasi belajar yang berbeda - beda juga dengan kondisi pengajaran guru yang berbeda - beda.
SMKN 26 Jakarta adalah salah satu sekolah kejuruan yang berada di Jakarta. Paket keahlian yang ada di sekolah tersebut terdiri dari Teknik Gambar Bangunan, Teknik Elektronika, Teknik Komputer Jaringan, Teknik Kendaraan Ringan, Otomotif dan Teknik Instalasi Pemnafaatan Tenaga Listrik. Kegiatan pembelajaran disekolah tersebut terdiri dari praktik dan teori.

Dalam paket keahlian Teknik Instalasi Pemanfaatan Tenaga Listrik, daftar mata pelajaran kejuruan untuk kelas $\mathrm{X}$ adalah Menganalisis Rangkaian Listrik, Gambar Teknik, Dasar - Dasar Elektronika, Pekerjaan Dasar Elektromekanik dan Simulasi Digital.

Mata pelajaran Menganalisis Rangkaian Listrik adalah mata pelajaran yang bertujuan untuk memberikan pemahaman kepada siswa tentang listrik dan rangkaiannya. Pada mata pelajaran ini, siswa kelas X SMKN 26 Jakarta paket keahlian TIPTL mempunyai nilai yang variatif sehigga mata pelajaran inilah yang menjadi objek penelitian dalam skripsi ini.

Siswa di sekolah ini khususnya pada paket keahlian Teknik Instalasi Pemanfaatan Tenaga Listrik, mempunyai guru yang variatif dalam mengajar dan siswa - siswanya mempunyai hasil belajar yang variatif juga dalam mata pelajaran Rangkaian Listrik. Hal ini menjadi latar belakang penulis untuk meneliti apakah terdapat hubungan yang positif dan signifikan antara persepsi siswa mengenai kompetensi pedagogik dan profesional guru dengan hasil belajar siswa mata pelajaran Rangkaian Listrik di SMKN 26 Jakarta.

\section{METODE}

Dilaksanakan di SMKN 26 Jakarta, pada bulan Mei-Juni 2016 dengan subjek penelitian adalah siswa kelas X jurusan Teknik Instalasi Listrik.

Populasi target dalam penelitian ini adalah seluruh siswa kelas X SMKN 26 Jakarta Paket keahlian Teknik Instalasi PemanfaatanTenaga Listrik yaitu sebanyak 59 siswa

Penentuan jumlah sampel dikembangkan dari rumus slovin dengan tingkat kesalahan 5\% dari populasi terjangkau yaitu sebesar 51 siswa.

Metode yang digunakan pada penelitian ini adalah penelitian kuantitatif dengan menggunakan survei dengan pendekatan asosiatif.

Variabel Bebas(Persepsi siswa mengenai kompetensi pedagogik dan profesional guru) 
didapatkan dari teknik survei yang dilakukan kepada responden.

Variabel terikat(Prestasi Belajar)didapatkan dengan teknik dokumentasi berupa nilai ulangan akhir semester (UAS).

Teknik pengumpulan data diambil dengan menggunakan metodepenyebaran angket berupa selembaran kepada subjek penelitian dan diisi saat itu juga dengan pengawasan peneliti. Uji persyaratan analisis menggunakan uji normalitas dan linearitas.Pengujian hipotesis menggunakan uji korelasi.

\section{HASIL DAN PEMBAHASAN}

\section{Persepsi Siswa Mengenai Kompetensi Pedagogik guru Rangkaian Listrik}

Dari kuesioner yang disebar kepada sampel, diperoleh data tertinggi 80 dan data terendah 50 . Rentang skor yang diperoleh adalah 30 dan rata rata sebesar 60,7.

\section{Persepsi Siswa Mengenai Kompetensi Profesional Guru Rangkaian Listrik}

Dari kuesioner yang disebar kepada sampel, diperoleh data tertinggi 40 dan data terendah 21 . Rentang skor yang diperoleh adalah 19 dan rata rata sebesar 31,3

\section{Hasil Pengujian Normalitas}

Tabel 1. Hasil Uji Normalitas Data $\mathrm{X}_{1}$ dan $\mathrm{Y}$

\begin{tabular}{|c|c|c|c|c|}
\hline Variabel & $\mathbf{L}_{\text {hitung }}$ & $\mathbf{L}_{\text {tabel }}$ & Keputusan & Kesimpulan \\
\hline $\begin{array}{c}\mathrm{X}_{1} \text { atas } \\
\mathrm{Y}\end{array}$ & 0,1152 & 0,1213 & $\begin{array}{c}\text { Terima } \\
\text { Ho }\end{array}$ & Normal \\
\hline
\end{tabular}

Tabel 2. Hasil Uji Normalitas Data $X_{2}$ dan $Y$

\begin{tabular}{ccccc}
\hline Variabel & $\mathbf{L}_{\text {hitung }}$ & $\mathbf{L}_{\text {tabel }}$ & Keputusan & Kesimpulan \\
\hline $\mathrm{X}_{2}$ atas & 0,100 & 0,121 & Terima & Normal \\
$\mathrm{Y}$ & 6 & 3 & Ho & \\
\hline
\end{tabular}

\section{Korelasi $\mathrm{X}_{\mathbf{1}}$ dengan $\mathrm{Y}$}

Berdasarkan hasil perhitungan, diperoleh $\mathbf{r}_{\mathrm{xy}}$ lebih besar daripada $r_{\text {tabel }}$ atau $0,34>0,279$, maka dalam penelitian ini terdapat hubungan yang positif antara variabel $\mathrm{X}_{1}$ dan $\mathrm{Y}$. Nilai thitung lebih besar dari $t_{\text {tabel }}$ yaitu 2,53 $>2,009$ yang berarti dapat disimpulkan bahwa hubungan persepsi siswa mengenai kompetensi pedagogik guru RL dengan hasil belajar siswa mata pelajaran RL mempunyai hubungan yang signifikan. nilai koefisien determinasi adalah sebesar $11,56 \%$.

\section{Korelasi $\mathbf{X}_{2}$ dengan $\mathbf{Y}$}

Berdasarkan hasil perhitungan, diperoleh $\mathrm{r}_{\mathrm{xy}}$ lebih besar daripada $r_{\text {tabel }}$ atau $0,41>0,279$, maka dalam penelitian ini terdapat hubungan yang positif antara variabel $\mathrm{X}_{2}$ dan $\mathrm{Y}$. nilai $\mathrm{t}_{\text {hitung }}$ lebih besar dari tabel yaitu 3,14>2,009 yang berarti dapat disimpulkan bahwa hubungan persepsi siswa mengenai kompetensi profesional guru RL dengan hasil belajar siswa mata pelajaran RL mempunyai hubungan yang signifikan. nilai koefisien determinasi adalah sebesar 16,81\%.

\section{Korelasi $\mathbf{X}_{\mathbf{1}}$ dengan $\mathbf{X}_{\mathbf{2}}$}

Berdasarkan hasil perhitungan, diperolehr $\mathrm{x}_{\mathrm{xy}}$ lebih besar daripada $r_{\text {tabel }}$ atau $0,59>0,279$, maka dalam penelitian ini terdapat hubungan yang positif antara variabel $X_{1}$ dan $X_{2}$. nilai $t_{\text {hitung }}$ lebih besar dari $t_{\text {tabel }}$ yaitu 5,11 $>2,009$ yang berarti dapat disimpulkan bahwa hubungan persepsi siswa mengenai kompetensi pedagogik guru RL dengan kompetensi profesional guru RL mempunyai hubungan yang signifikan. nilai koefisien determinasi adalah sebesar $34,81 \%$.

\section{Korelasi $X_{1}$ dan $X_{2}$ dengan $Y$}

Berdasarkan hasil perhitungan, diperoleh Karena $r_{x y}$ lebih besar daripada $r_{\text {tabel }}$ atau 0,43>0,279, maka dalam penelitian ini terdapat hubungan yang positif antara variabel $\mathrm{X}_{1}$ dan $\mathrm{X}_{2}$ dengan $\mathrm{Y}$. nilai $t_{\text {hitung }}$ lebih besar dari $t_{\text {tabel }}$ yaitu 4,57 $>2,009$ yang berarti dapat disimpulkan bahwa hubungan persepsi siswa mengenai kompetensi pedagogik dan profesional guru RL dengan hasil belajar siswa mempunyai hubungan yang signifikan. nilai koefisien determinasi adalah sebesar 18,49\%.

\section{KESIMPULAN DAN SARAN \\ Kesimpulan}

1. Ada hubungan yang positif dan signifikan antara antara persepsi siswa mengenai kompetensi pedagogik guru RL dengan hasil 
belajar siswa mata pelajaran RL. Ditunjukkan dengan besarnya koefisien korelasi sebesar 0,34 dan signifikasi korelasi sebesar 2,53.

2. Ada hubungan yang positif dan signifikan antara antara persepsi siswa mengenai kompetensi profesional guru RL dengan hasil belajar siswa mata pelajaran RL. Ditunjukkan dengan besarnya koefisien korelasi sebesar 0,41 dan signifikasi korelasi sebesar 3,14.

3. Ada hubungan yang positif dan signifikan antara antara persepsi siswa mengenai kompetensi pedagogik dan profesional guru RL dengan hasil belajar siswa mata pelajaran RL. Ditunjukkan dengan besarnya koefisien korelasi sebesar 0,43 dan signifikasi korelasi sebesar 4,57.

\section{Saran}

1. Kepala Sekolah

Hasil penelitian ini menerangkan bahwa persepsi siswa mengenai kompetensi pedagogik dan profesinal guru mempunyai hubungan dengan hasil belajar siswa. Maka dari itu peneliti memberikan saran kepada kepala sekolah SMK, agar dapat meningkatkan kompetensi yang harus dimiliki oleh guru terutama kompetensi pedagogik dan profesional sesuai dengan yang terdapat pada UU. Hal ini dapat dilkukan dengan cara mengevaluasi kompetensi guru kemudian merancang program peningkatan kompetensi guru agar sesuai dengan UU.

2. Guru

Hasil penelitian ini menerangkan bahwa persepsi siswa mengenai kompetensi pedagogik dan profesinal guru mempunyai hubungan dengan hasil belajar siswa. Maka dari itu peneliti memberikan saran guru SMK, agar dapat meningkatkan kompetensi yang dimiliki terutama kompetensi pedagogik dan profesional sesuai dengan yang terdapat pada UU. Hal ini dapat dilkukan dengan cara dengan mengikuti pelatihan kompetensi guru.

3. Siswa

Hasil penelitian ini menerangkan bahwa persepsi siswa mengenai kompetensi pedagogik dan profesinal guru mempunyai hubungan dengan hasil belajar siswa. Maka dari itu peneliti memberikan saran kepada siswa SMK, agar dapat memperbaiki persepsinya meningkatkan kompetensi guru terutama kompetensi pedagogik dan profesional. Hal ini dapat dilkukan dengan cara mengevaluasi kompetensi guru kemudian memberikan masukan kepada guru berkenaan dengan kompetensi yang tidak sesuai dengan guru.

4. Peneliti Selnjutnya

Penelitian ini dibatasi pada kompetensi pedagogik dan profesional guru, sehingga peneliti memberikan saran kepada peneliti selanjutnya untuk meneliti kompetensi guru lainnya yaitu kompetensi sosial dan kepribadian.

\section{DAFTAR PUSTAKA}

Arikunto. Suharsimi. (2013)Prosedur Penelitian, (Jakarta: Rineka Cipta

Departemen pendidikan nasional (2014), Kamus Besar Bahasa Indonesia. Jakarta : balai pustaka

Djamarah, Syaiful Bahir dan Zain Aswan. (2010). Strategi Belajar Mengajar. Jakarta: Rineka Cipta.

Imron Ali. (2011). Menejemen Peserta Didik Berbasis Sekolah. Jakarta : Bumi Aksara

Purwanto. (2013). Evaluasi Hasil Belajar. Yogyakarta : Pustaka Pelajar

Riswandi.(2013). Psikologi komunikasi. Yogyakarta : graha ilmu

Rugaiyah, sismati atiek. (2011). Profesi Kependidikan. Bogor : ghalia indonesia

Sardiman a.m. (2007). Interaksi Dan Motivasi Belajar Mengajar . Jakarta : pt raja grafindo persada

Sardiman a.m. (2014). Interaksi Dan Motivasi Belajar Mengajar . Jakarta : pt raja grafindo persada 
Siregar, Eveline dan Nara Hartini. (2011). Teori Belajar Dan Pembelajaran. Bogor : ghalia indonesia

Slameto. (2010). Faktor - Faktor yang Mempengaruhi. Jakarta : Rineka Cipta

Sugiyono. (2010). Metode Penelitian Kuantitatif, Kualitatif, Dan R\&D. Bandung: alfabeta.

Sugiyono. (2008). Metode Penelitian

Pendidikan. Bandung: alfabeta
Trianto. (2007). Model Pembelajaranterpadu Dalam Teori Dan Praktek. Jakarta : prestasi pustaka

Wahab, Rohmalina. (2015). Psikologi Belajar. Jakarta : Raja Grafindo Persada

Wahyudi, Imam. (2012). Panduan Lengkap UjiSertifikasi Guru.Jakarta 